\title{
Pyrolysis-GC/MS for the identification of macromolecular components in historical recipes
}

\section{Chiara Riedo, Dominique Scalarone \& Oscar Chiantore}

Analytical and Bioanalytical Chemistry

ISSN 1618-2642

Volume 401

Number 6

Anal Bioanal Chem (2011) 401:1761-1769

DOI 10.1007/s00216-011-5142-9

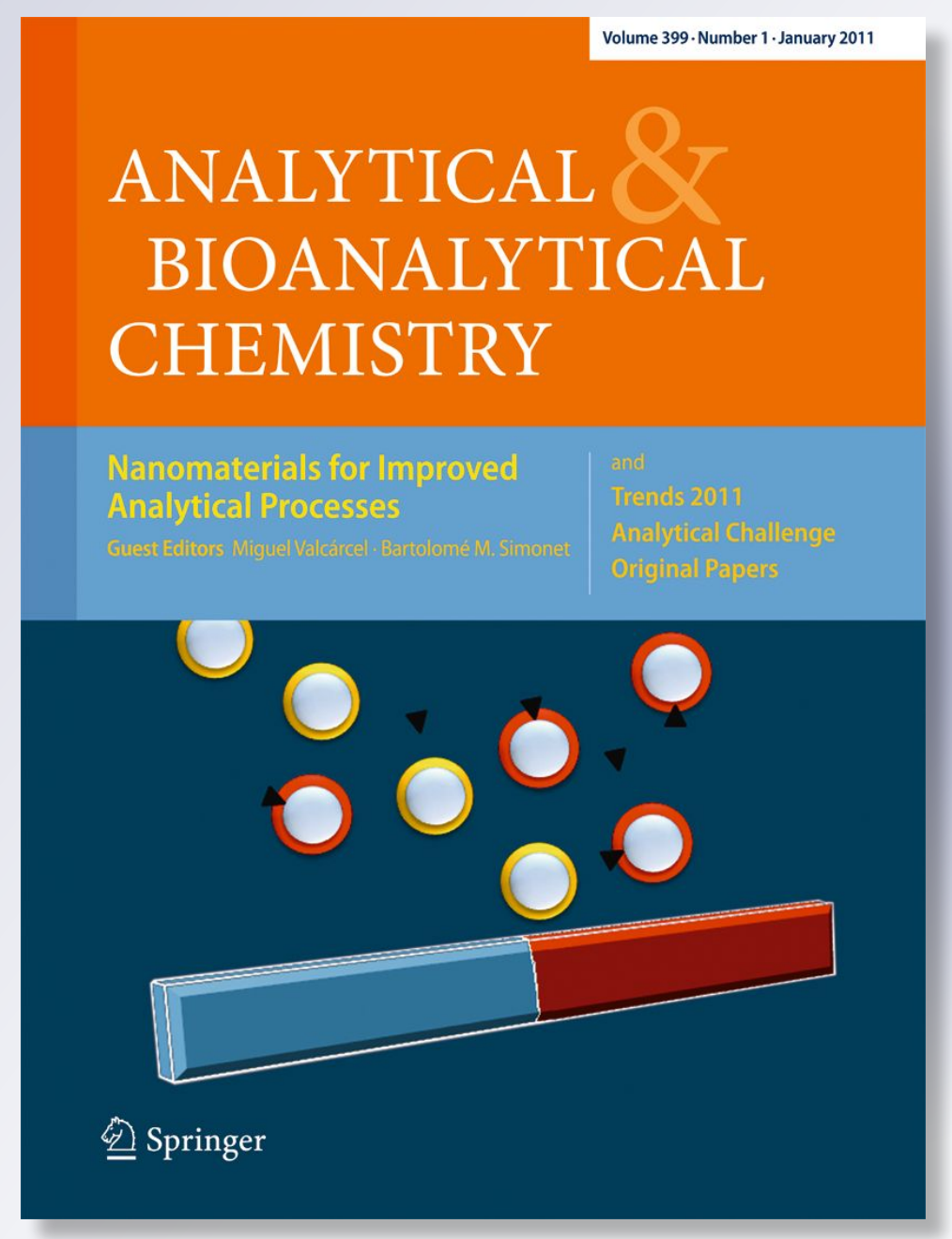

留 Springer 
Your article is protected by copyright and all rights are held exclusively by SpringerVerlag. This e-offprint is for personal use only and shall not be self-archived in electronic repositories. If you wish to self-archive your work, please use the accepted author's version for posting to your own website or your institution's repository. You may further deposit the accepted author's version on a funder's repository at a funder's request, provided it is not made publicly available until 12 months after publication. 


\title{
Pyrolysis-GC/MS for the identification of macromolecular components in historical recipes
}

\author{
Chiara Riedo • Dominique Scalarone - Oscar Chiantore
}

Received: 31 March 2011 /Revised: 22 May 2011 / Accepted: 24 May 2011 /Published online: 3 June 2011

(C) Springer-Verlag 2011

\begin{abstract}
Analytical pyrolysis with thermally assisted hydrolysis and methylation was employed to investigate ancient ointments collected from Spanish vessels coming from the sixteenth century pharmacies. The ointments were reproduced on the basis of historical recipes and characterization was made in comparison with real samples. Characteristic markers indicate the presence of beeswax, of animal and plant lipids, and of natural resins. Analyses of old samples are consistent with the modern reproductions and with the analysis of raw materials. Multivariate data analysis was used to discriminate between the different types of lipidic materials, also in connection with their relative amount in the samples.
\end{abstract}

Keywords Py-GC/MS · Ointments · Historical recipes . Thermally assisted hydrolysis and methylation · Lipids . Resins

\section{Introduction}

The study of ancient preparations in cosmetics and medicine is quite interesting because it provides information about cultural habits and scientific and technological knowledge of past civilization.

For example, studies carried on Egyptian make-up powders showed the presence of organic and inorganic

Published in the special issue Analytical Chemistry to Illuminate the Past with guest editor Maria Perla Colombini.

C. Riedo $(\bowtie) \cdot$ D. Scalarone $\cdot$ O. Chiantore

Department of IPM Chemistry and NIS-Centre of Excellence,

University of Turin,

Via Pietro Giuria no. 7,

10125 Torino, Italy

e-mail: chiara.riedo@unito.it compounds even with some of synthetic origin, proving that ancient Egyptians had the knowledge of wet chemistry $[1,2]$. Also more recent materials can provide interesting information, for example about the development of surgery and medical practices in the sixteenth century [3].

Some historical texts give accounts on recipes of preparations, but in most cases, ingredients and modality of making are not disclosed; therefore, analytical characterization of ancient samples becomes necessary to understand their compositions. Furthermore, labels on vessels may be wrong or absent, or the terminology used for description may be obsolete and not comparable with that used at the present.

Residues found in archaeological vessels often contain a large variety of constituents, both organic and inorganic, and of natural origin as plant gums and resins, waxes, and lipids. These materials are complex and often show macromolecular characteristics that add further difficulty in chemical characterization. The analysis is furthermore complicated by the presence of mixtures or contaminants and by the changes in original raw ingredients composition due principally to ageing processes and/or to chemical modification during ointments preparations. Ageing processes may derive not only from the environmental conditions to which the object has been exposed, but also from inappropriate conservation conditions adopted after its discovery and acquisition.

For the analysis of samples with complex chemical composition, the technique of gas chromatography coupled with mass spectrometry is particularly useful. Due to their polymeric features, some materials require a chemical treatment before chromatographic analysis, but often the sample amounts coming from ancient vessels are not sufficient to perform such procedures. Analytical pyrolysis may overcome these difficulties in a twofold way. Firstly, 
by obtaining sample decomposition before chromatographic analysis the polymeric structures are fragmented and reduced to sizes compatible with the gas chromatographic separation. Secondly, the possibility of applying on-line derivatization provides further simplification of the analytical procedure, allowing to obtain in a single step decomposition, derivatization, separation, and identification of analytes. For these reasons, analytical pyrolysis is a suitable tool for studying samples of archaeological and artistic provenance [4].

In the course of this study, carried on in collaboration with other Italian research groups, on samples coming from Aboca Museum (Sansepolcro, Arezzo, Italy) and contained in characteristic pharmaceutical vessels called albarelli, fabricated in Spain and dated from the sixteenth and seventeenth century, we have investigated the chemical composition of historical ointments and the molecular structures of the components. The more comprehensive results were obtained by means of pyrolysis-gas chromatography/mass spectrometry (Py-GC/MS) with thermally assisted hydrolysis and methylation (THM) employing tetramethylammonium hydroxide (TMAH). This technique is widely used in the field of cultural heritage, but not deeply tested on ointments and similar materials, due to the complex nature of this type of samples.

This study is part of a multi-analytical investigation, and Py-GC/MS, in this context, has the role of providing information about the composition of excipients, being a rapid method which requires very small amount of material and suitable for macromolecular components.

Following the available historical sources, a first reconstruction of original recipes could be done. The ointments were reproduced as modern preparations, and they were analyzed for comparison with the real samples. The modern preparations were also artificially aged. In this way, it is possible to ascertain if the technique is capable of providing information about the samples suitable for identification of the ointment on the basis of excipients and other macromolecular components. With this aim, multivariate data analysis was used to compare analysis performed on raw materials, ointment reproduction, and real samples. Attention was focused on lipidic fraction, for that original material attribution is critical.

Moreover, the comparison of results allows to understand if the raw materials used in the past were the same as those nowadays available and if the ancient producers really followed the recipes reported in literature.

\section{Materials and methods}

The four ancient samples coming from Aboca Museum (Sansepolcro, Arezzo, Italy) are a set of ointments recovered from vessels dated from the sixteenth and seventeenth centuries. Their original containers have labels that suggest the names of the recipes.

Unguentum althea (inventory no. 5007) is a solid and brown material. Unguentum pro Igne (50015), Unguentum Colophonie (50017), and Unguentum rosatum (50509) are reddish-brown sticky pastes. Sample 50015 and 50017 smell rancid.

For comparison with the original samples, the preparations were reproduced on the basis of ancient recipes. The sources of recipes were in particular Farmacopea Augustana (A. Occo, 1597), Ricettario Fiorentino, Farmacopea Hispanica, Nuovo Formulario Magistrale (A. Bouchardat), and Abrégé de Matière médicale et de Thérapeutique (C. Binz). In these ancient books also, the description of raw materials was found. The finding of historical recipes and raw materials and the reproduction of ointments were done at the Faculty of Pharmacy of Università degli Studi di Modena e Reggio Emilia (Italy).

The composition of ointments obtained from ancient historical sources is listed in Table 1. All the raw materials were individually analyzed and some of them submitted to accelerated artificial ageing. In particular ozonolysis was applied, considered to be one of the strongest oxidation processes. This treatment was also applied to some of the preparations reproducing ancient ointments. Ageing with ozonolysis was done at the Università degli Studi di Milano Bicocca, Department of Scienze Ambientali e del Territorio (Milano, Italy). For lipids also binary and ternary mixtures in different proportion were analyzed, to obtain a reference data set for chemometric treatment.

Raw materials, new preparations, and historical samples were analyzed using Py-GC/MS with THM [5]. The derivatizant used was TMAH in aqueous solution at $25 \%$ $w / w$ (Sigma-Aldrich-MI-Italy).

Small portions of the samples were loaded in a quartz tube closed with two small pieces of quartz wool, then $5 \mu \mathrm{L}$ of TMAH in aqueous solution was added using a microsyringe. Pyrolysis was performed at $600{ }^{\circ} \mathrm{C}$ with CDS Pyroprobe 1000 (Analytical Inc., USA) filament pyrolyzer directly connected to GC/MS system. Pyrolysis chamber was fluxed with helium. The GC is a $6890 \mathrm{~N}$ Network GC System (Agilent Technologies, USA) gas chromatograph with a methyl-phenyl-polysiloxane cross-linked 5\% phenyl methyl silicone $(30 \mathrm{~m}, 0.25 \mathrm{~mm}$ i.d., $0.25 \mu \mathrm{m}$ film thickness) capillary column. The temperature program was: $50{ }^{\circ} \mathrm{C}$ for $2 \mathrm{~min}$, then a temperature ramp to $300{ }^{\circ} \mathrm{C}$ (heating rate $10{ }^{\circ} \mathrm{C} / \mathrm{min}$ to $130{ }^{\circ} \mathrm{C}, 5{ }^{\circ} \mathrm{C} / \mathrm{min}$ to $180{ }^{\circ} \mathrm{C} / \mathrm{min}$ then $15{ }^{\circ} \mathrm{C} / \mathrm{min}$ to $300{ }^{\circ} \mathrm{C}$, held for $5 \mathrm{~min}$ ). The temperature of the injector and of the Py-GC interface was kept at $280{ }^{\circ} \mathrm{C}$. The carrier gas was helium $(1.0 \mathrm{~mL} / \mathrm{min})$, and the split ratio was $1 / 20$ of the total flow. The mass spectrometer coupled to the GC apparatus was a 5973 Network 
Table 1 Nomenclature of the reproduced recipes with ingredients and relative abundance of lipidic fractions. In bold: ingredients recognized with THM
* Ingredients identified with THM in bold

\begin{tabular}{|c|c|c|c|c|}
\hline \multirow[t]{2}{*}{ Name } & \multirow[t]{2}{*}{ Raw material* } & \multicolumn{3}{|c|}{ Lipids distribution (\%) } \\
\hline & & Pig suet & Oils & Beeswax \\
\hline Unguentum Rosatum $\mathrm{I}_{\mathrm{A}}$ & $\begin{array}{l}\text { Pig suet } \\
\text { Fresh red rose petals } \\
\text { Rose water } \\
\text { Almond oil }\end{array}$ & 92 & 8 & 0 \\
\hline Unguentum Rosatum $\mathrm{I}_{\mathrm{B}}$ & $\begin{array}{l}\text { Pig suet } \\
\text { Fresh red rose petals }\end{array}$ & 100 & 0 & 0 \\
\hline Unguentum Rosatum $\mathrm{I}_{\mathrm{C}}$ & $\begin{array}{l}\text { Pig suet } \\
\text { Beeswax } \\
\text { Rose water }\end{array}$ & 67 & 0 & 33 \\
\hline Unguentum Pro Igne $\mathrm{III}_{\mathrm{A}}$ & $\begin{array}{l}\text { Turnip juice } \\
\text { Pig suet } \\
\text { Olive oil } \\
\text { Beeswax } \\
\mathrm{PbO} \text { (litargirio d'argento) }\end{array}$ & 39 & 31 & 29 \\
\hline Unguentum Pro Igne $\mathrm{III}_{\mathrm{B}}$ & $\begin{array}{l}\text { Turnip juice } \\
\text { Pig suet } \\
\text { Olive oil } \\
\text { Beeswax }\end{array}$ & 38 & 32 & 29 \\
\hline Unguentum Althea $\mathrm{VI}_{\mathrm{A}}$ & $\begin{array}{l}\text { Althaea roots } \\
\text { Line seeds } \\
\text { Foenum graecum seeds } \\
\text { Olive oil } \\
\text { Beeswax } \\
\text { Pine resin }\end{array}$ & 0 & 80 & 20 \\
\hline Unguentum Althea $\mathrm{VI}_{\mathrm{B}}$ & $\begin{array}{l}\text { Althaea mucilage } \\
\text { Line mucilage } \\
\text { Foenum graecum mucilage } \\
\text { Pig suet } \\
\text { Powdered curcuma roots } \\
\text { Yellow beeswax } \\
\text { Pine resin }\end{array}$ & 86 & 0 & 14 \\
\hline Unguentum Colophonia $\mathrm{VII}_{\mathrm{A}}$ & $\begin{array}{l}\text { Olive oil } \\
\text { Beeswax } \\
\text { Colophony } \\
\text { Mastic } \\
\text { Galbanum } \\
\text { Incense }\end{array}$ & 0 & 86 & 14 \\
\hline Unguentum Colophonia $\mathrm{VII}_{\mathrm{B}}$ & $\begin{array}{l}\text { Colophony } \\
\text { Gum arabic }\end{array}$ & 0 & 0 & 0 \\
\hline
\end{tabular}

MASS Selective Detector (Agilent Technologies, USA). Mass spectra were recorded under electron impact at $70 \mathrm{eV}$, scan range $40-600 \mathrm{~m} / \mathrm{z}$. The interface was kept at $280{ }^{\circ} \mathrm{C}$, ion source at $230{ }^{\circ} \mathrm{C}$, and quadrupole mass analyzer at $150{ }^{\circ} \mathrm{C}$.

All instruments were controlled by Enhanced Chem Station (ver. 9.00.00.38) software. The mass spectra assignment was done with NIST2008 library and by comparison with the literature data.

\section{Results and discussion}

Raw materials and modern reproductions

Analysis of the raw materials listed in Table 1 showed that many of them are not recognizable by means of specific markers. For example, pure turnip juice (data not reported here), one of the ingredients of Unguentum pro Igne, only shows the presence of some carbohydrate markers [5-7] 
and other non-identified compounds. It was therefore not possible to recognize the presence of this ingredient in a complex sample, in particular, when other carbohydratebased materials are present. In the pyrogram of Unguentum pro Igne $\mathrm{III}_{\mathrm{A}}$ aged with ozonolysis (Fig. 1) turnip juice could not be identified. Other examples for this type of compounds are rose petals or rose water, contained in the recipes of Unguentum rosatum (not shown) and plant extracts as althea roots, line seeds, and foenum graecum seeds mucilages contained in Unguentum althea (Fig. 2).

Another problem derives from materials easily identifiable in reference standards, but non-recognizable in real samples. One example is given by mastic, a triterpenic resins. Pyrogram of pure mastic (Fig. 3) shows characteristic markers of triterpenic compounds at high retention times, not very intense, and in some cases, affected by background noise. Some of these markers are moronic acid, oleanoic acid, oleanonic aldehyde, and olean-18-ene [8,9]. The identification of this resin is extremely difficult, particularly in aged samples. In the modern reproduction of unaged Unguentum Colophonia, only three of the triterpenic markers present in the standard are found, with mass spectra extremely affected by background signals. No one signal of the mastic has been identified in the same reproduction after ozonolysis ageing (results not shown because only background signals are present).

The materials for which identification was successful are the lipids (pig suet, plant oils, and beeswax), diterpenic resins, and gum arabic.

For lipids, it is necessary to elaborate further, being these materials the most abundant in ointment compositions according to the data found in the ancient recipes. In addition, lipids are first in the ranking of temporal stability of the biomarkers, followed by carbohydrates, proteins, and nucleotides. Their resistance to decay and persistence at the original site of deposition make them excellent candidates for use as biomarkers in archaeological studies [10].

Among the three classes investigated during the present study, beeswax is easily recognizable by $\mathrm{Py}-\mathrm{GC} / \mathrm{MS}$, thanks to the characteristic $n$-alkanes/1-alkenes pattern at low retention times and to the long-chain alkanes/fatty acid series. In particular, long-chain fatty acids distribution, dominated by the abundance of $\mathrm{C} 24$ fatty acids, makes a kind of fingerprint that allows univocal identification of beeswax in a mixture [11], also at low concentration.

Regarding the differentiation between plant oils and animal fats, in the present work, it is highlighted that with THM method it is not possible to identify the branched fatty acids, characteristics in animal fats $[12,13]$. Drastic pyrolysis conditions destroy the triglycerides, whose distribution should be useful for lipids classification [12]. The only marker identified in pig suet, not present in plant oils, is the $\mathrm{C} 17$ fatty acid, while all other fatty acids are present in both types of lipids, although with different distributions. For example, it is possible to appreciate that the stearic acid relative abundance is higher in pig suet than in plant oil. In Fig. 2, this feature is well depicted: sample $\mathrm{VI}_{\mathrm{A}}$ and sample $\mathrm{VI}_{\mathrm{B}}$ (both aged with ozone) contain the same basic ingredients (see Table 1 and 2), but plant oil is present in $\mathrm{VI}_{\mathrm{A}}$ whereas pig suet is present in $\mathrm{VI}_{\mathrm{B}}$. In the pyrogram in Fig. $2 b\left(\mathrm{VI}_{\mathrm{B}}\right)$, the presence of pig fat is shown by $\mathrm{C} 17$ fatty acids and also by the stearic acid abundance comparable with that of oleic acid. In the pyrogram of $\mathrm{VI}_{\mathrm{A}}$, the most abundant fatty acid is oleic acid and $\mathrm{C} 17$ fatty acids are not detected consistently with the presence of plant oil.

When plant oil and pig suet are simultaneously present, the resulting pyrogram is similar to that of pig suet, and it is therefore not possible to know if a plant oil is also present. An example is given by Unguentum pro Igne $\mathrm{III}_{\mathrm{A}}$, containing both olive oil and pig suet. In the pyrogram
Fig. 1 Pyrogram of reproduction of Unguetum pro Igne (recipe $\mathrm{III}_{\mathrm{A}}$ ) aged with ozonolysis

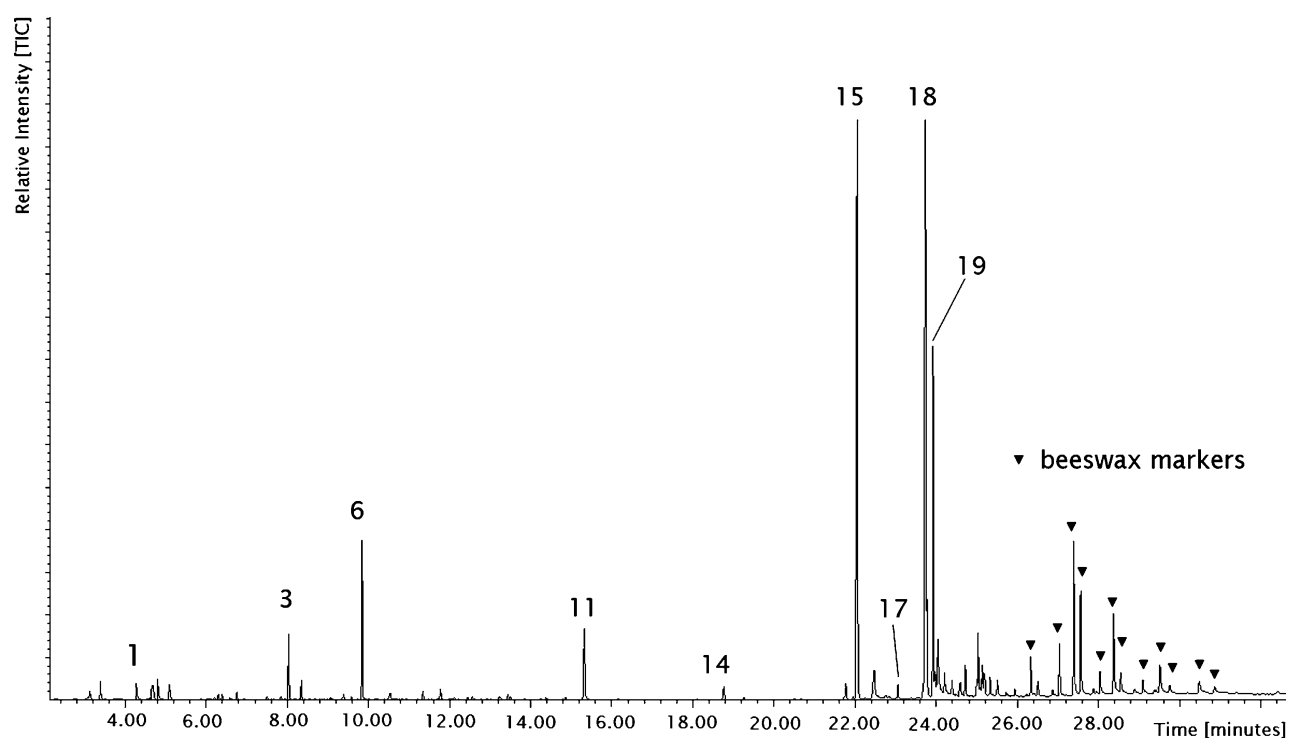


Fig. 2 Pyrogram of reproduction of two historical recipes of

Unguentum althea $\left(\mathrm{VI}_{\mathrm{A}}\right.$ and $\left.\mathrm{VI}_{\mathrm{B}}\right)$

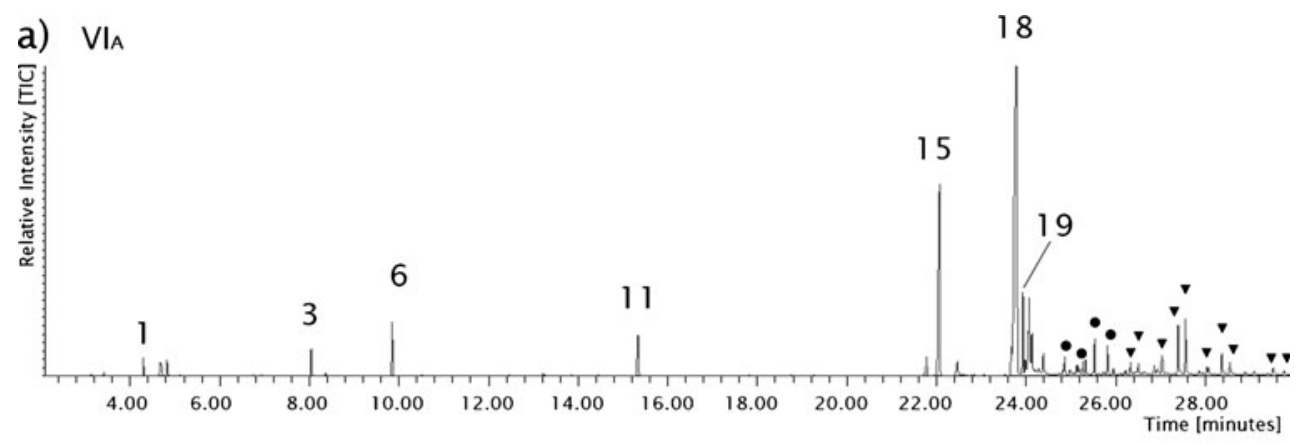

b) $\mathrm{VlB}_{\mathrm{B}}$

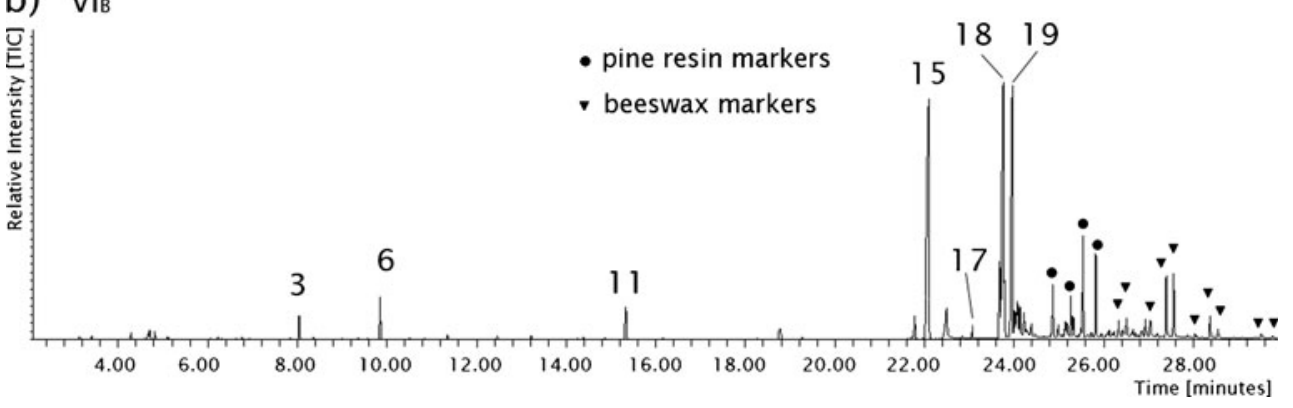

(Fig. 1), the presence of $\mathrm{C} 17$ fatty acids is detected together with stearic acid more abundant than in a vegetable oil, as a result of the presence of an animal fat in the sample. However, it is not possible to prove that olive oil is present, due to the non-existence of specific marker compounds.

For identification of lipids in a mixture, and in particular for differentiation of plant oils from animal fats, it is therefore necessary that a more general approach, not based on individual markers but on semiquantitative treatment of the pyrolysis data, is used as described in a following paragraph.

The study of artificially aged raw materials and ointment reproductions showed that ozonolysis strongly affects all

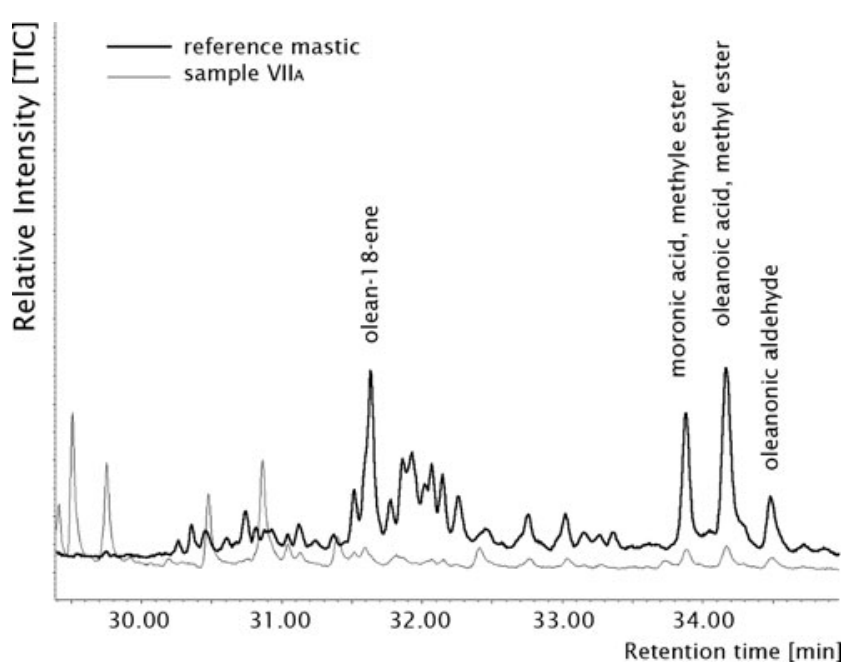

Fig. 3 Comparison between high retention time region of the pyrograms obtained from Unguentum Colophoniae: recipe $\mathrm{VII}_{\mathrm{A}}$ and ancient sample, showing mastic markers the components, and more particularly, the oils. Pig fat and semi-solid mixtures showed minor changes because oxidation took place only on the sample surfaces. In the reproduced ointments, a small amount of nonanoic and nonandioic acid (peaks 6 and 11), and nonanal (peaks 3) have been identified, which are typical products deriving from the oxidation of fatty acids with unsaturation on carbon atom in position 9 [14].

\section{Ancient samples}

The pyrogram of Unguentum pro Igne (50015) is shown in Fig. 4a, and the peak assignment is listed in Table 1. Markers of beeswax are well identified, confirming the presence of this material in the preparation. Also markers of lipidic material are found and the presence of peak 17 (C17 fatty acid methyl ester) suggests that the sample contains animal fat. Vegetable oils may be also present but, as previously discussed, they are not unequivocal markers which can be exploited. Peaks 7 to 11 suggest that material is aged. The possible presence of turnip juice and $\mathrm{PbO}$, indicated by ancient recipes, cannot be detected with pyrolysis, as shown in the results from reference materials previously discussed.

The Unguentum althea (5007) sample appears contaminated by high molecular weight hydrocarbons (shown in Fig. 4d) not referable to the presence of natural wax. These molecules may come from the packaging material that came in contact with the sample.

Although covered by these contaminant signals, it was possible to identify the presence of some fatty acids (peaks 15 and 18) that may be indicative of lipidic 
Table 2 Assignments of compounds identified in pyrograms of ancient samples, reproduction of historical recipes and raw material

\begin{tabular}{|c|c|c|c|c|}
\hline Peak no. & $\mathrm{RT}[\mathrm{min} .]^{*}$ & Scan & Assignment & $m / z^{* *}$ \\
\hline 1 & 4,62 & 400 & 1,2,3-trimethoxy-propane & $45,58, \mathbf{5 9}, 89,102$ \\
\hline 2 & 5,07 & 471 & esanoic acid, methyl ester & $41,4374,87,99$ \\
\hline 3 & 8,03 & 936 & nonanal & $41,56, \mathbf{5 7}, 70,98$ \\
\hline 4 & 8,32 & 982 & octanoic acid, methyl ester & $43,55,74,87,127$ \\
\hline 5 & 9,18 & 1118 & octanoic acid & $41,43,55,60,73$ \\
\hline 6 & 9,81 & 1217 & nonanoic acid, methyl ester & $41,43,55,74,87$ \\
\hline 7 & 10,59 & 1339 & nonanoic acid & $41,55,57,60,73$ \\
\hline 8 & 11,31 & 1453 & decanoic acid, methyl ester & $41,43,55,74,87$ \\
\hline 9 & 11,66 & 1507 & eptandioic acid, dimethyl ester & $55,59,69,74,115$ \\
\hline 10 & 13,42 & 1785 & octandioic acid, dimethyl ester & $69,74,97, \mathbf{1 2 9}, 138$ \\
\hline 11 & 15,31 & 2082 & nonandioic acid, dimethyl ester & $55,74,83,111, \mathbf{1 5 2}$ \\
\hline 12 & 16,11 & 2208 & nonandioic acid, mono-methyl ester & $41,43,55,74,152$ \\
\hline 13 & 17,24 & 2386 & decandioic acid, dimethyl ester & $\mathbf{5 5}, 74,97,98,125$ \\
\hline 14 & 18,72 & 2619 & tetradecanoic acid, methyl ester & $41,43,55,74,87$ \\
\hline 15 & 22,06 & 3143 & esadecanoic acid, methyl ester & $41,43,55,74,87$ \\
\hline 16 & 22,48 & 3211 & esadecanoic acid & $41, \mathbf{4 3}, 57,60,73$ \\
\hline 17 & 23,04 & 3298 & heptadecanoic acid, methyl ester & $43,74,75,87,143$ \\
\hline 18 & 23,70 & 3403 & 9-octedecanoi acid, methyl ester & $\mathbf{5 5}, 69,74,83,97$ \\
\hline 19 & 23,92 & 3436 & octadecanoic acid, methyl ester & $43,55, \mathbf{7 4 , 7 5 , 8 7}$ \\
\hline 20 & 24,19 & 3479 & octadecanoic acid & $\mathbf{4 3}, 55,57,60,73$ \\
\hline 21 & 24,38 & 3509 & 9,12-octadecanoic acid, methyl ester & $55,67,79,81,95$ \\
\hline 22 & 24,84 & 3582 & sandaracopimaric acid, methyl ester & $91, \mathbf{1 2 1}, 257,301,316$ \\
\hline 23 & 25,25 & 3645 & isopimaric acid, methyl ester & $91,105,119,121, \mathbf{2 4 1}$ \\
\hline 24 & 25,32 & 3656 & eicosanoic acid, methyl ester & $41,43,55,74,87$ \\
\hline 25 & 25,48 & 3682 & 6-dehydroabietic acid, methyl ester & $41,43,195,197,237$ \\
\hline 26 & 25,52 & 3689 & acid dehydroabietic, mehtyl ester & $43,141, \mathbf{2 3 9}, 240,299,314$ \\
\hline 27 & 26,19 & 3794 & tetradehydroabietic acid, 7-methoxy-, methyl ester & $227,267,282, \mathbf{3 4 2}, 343$ \\
\hline 28 & 26,32 & 3818 & pentacosane & $43, \mathbf{5 7}, 71,85,361$ \\
\hline 29 & 26,50 & 3842 & docosanoi acid, methyl ester & $43,74,75,87,354$ \\
\hline 30 & 26,92 & 3910 & 7-oxodehydroabietic acid, methyl ester & $187,253,254,328,313$ \\
\hline 31 & 27,03 & 3926 & $n$-tetracosanol & $43,55, \mathbf{5 7}, 83,97$ \\
\hline 32 & 27,39 & 3982 & heptacosane & $41,43, \mathbf{5 7}, 71,85$ \\
\hline 33 & 27,55 & 4008 & tetracosanoic acid, methyl ester & $55,74,75,87,382$ \\
\hline 34 & 27,87 & 4058 & 15-hydroxy-7-oxodehydroabietic acid, methyl ester & $43,269, \mathbf{3 2 9}, 330,344$ \\
\hline 35 & 28,02 & 4083 & 1-exacosanol & $43,55, \mathbf{5 7}, 83,97$ \\
\hline 36 & 28,36 & 4136 & nonacosane & $43,55, \mathbf{5 7}, 71,85$ \\
\hline 37 & 28,54 & 4164 & hexacosanoic acid, methyl ester & $43,55,57,74,87$ \\
\hline 38 & 29,08 & 4250 & 1-octacosanol & $43,55, \mathbf{5 7}, 83,97$ \\
\hline 39 & 29,50 & 4315 & hentriacontane & $43,55, \mathbf{5 7}, 71,85$ \\
\hline 40 & 29,75 & 4354 & octacosanoic acid, methyl ester & $43,57,74,87,438$ \\
\hline 41 & 30,47 & 4468 & 1-triacontanol & $43,55, \mathbf{5 7}, 97,83$ \\
\hline
\end{tabular}

* RT: Retention Time

** Principal ion in bold

component. Notwithstanding the partial interference with hydrocarbon compounds, the markers of a diterpenic resins are well identifiable (peaks 22, 23, 25, 26, and 30) [15]. The ancient recipe for Unguentum althea suggests pine resin in the ingredient list, therefore this sample, even if deeply contaminated, might really be a remain of Unguentum althea, as suggested by the label on the container. 
Fig. 4 Pyrograms of the ancient sample from Aboca Museum

(Sansepolcro, Italy): a)

Unguentum pro Igne (50015), b)

Unguentum Colophoniae

(50017), c) Unguentum rosatum (50509), and d) Unguentum althea (5007)
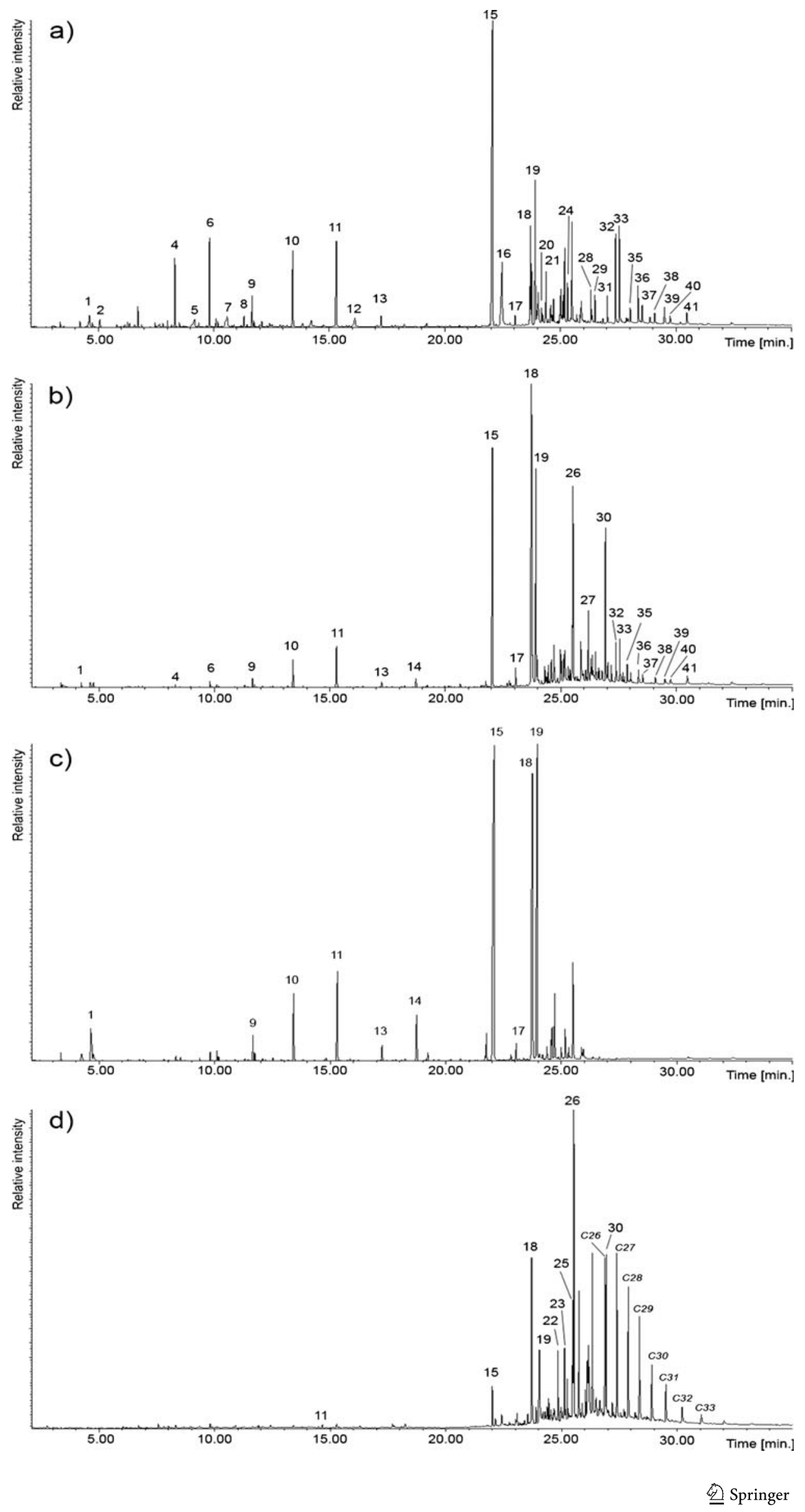
In the pyrogram of Unguentum rosatum (50509; Fig. 4c), C17 fatty acid methyl ester (peak 17) and the high amount of stearic acid (peak 19) suggest that the sample contains animal fat. As commented previously, oil may be also present but it is not possible to prove. With the method employed, rose petals and rose water, suggested by ancient recipes, could not be identified neither in ancient samples nor in the modern preparations.

The pyrogram of Unguentum colophonia (50017; Fig. 4b) shows characteristic markers of aged lipids, in particular high amounts of fatty acids (palmitic and stearic, respectively, peaks 15 and 19) and the heptadecanoic acid methyl ester (peak 17) suggesting the presence of animal fat. Beeswax may be also present, as shown by the long-chain hydrocarbons and fatty acids methyl esters. Peaks 26 (acid dehydroabietic, methyl ester) and 30 (7-oxodehydroabietic acid, methyl ester) are indicative of a ditherpenic resin, which is in good correspondence with the oinment's name.

\section{Lipids in Aboca Museum samples}

For correct identification of lipids that represent the major fraction in the composition of the investigated ointments, the old samples from Aboca Museum were compared with the modern reproductions and with some of the reference compounds by using principal component analysis. In particular, peak integrations of the main markers were used to ascertain the type of lipids contained in the sample, and in what amount. In Fig. 5, the biplot of scores and loadings on $\mathrm{PC} 1$ and $\mathrm{PC} 2$ are shown. It is possible to observe that the samples are located in different regions according the amounts of different ingredients, as shown by the arrows.

Sample 5007 (Unguentum althea) is located in the region dominated by the presence of unaged oils and by the $\mathrm{VI}_{\mathrm{A}}$ and $\mathrm{VII}_{\mathrm{A}}$ unaged and aged reference preparations. The latter preparations contain only oil and not pig fat; therefore, it is possible to confirm that in sample 5007 animal fat is not present.

The sample 50509 (Unguentum rosatum) is located in the zone with samples containing pig fat: IA, IB, and IC unaged reproductions of Unguentum rosatum, VIB both unaged and ozonyzed, pig fat reference sample alone, and in mixture with $10 \%$ of olive oil. These observations suggest that sample 50509 contains pig fat only or pig fat and oil, with higher amount of the first ingredient. The intermediate position of sample 50017 (Unguentum Colophonie) indicates that the sample contains pig fat and also vegetable oil and beeswax in comparable proportions. Sample 50015 (Unguentum pro Igne) also is located in an intermediate position, but translated in the direction of higher beeswax and lower pig fat concentration.

Samples 50509, 50017, and 50015 are located in the left part of the plot, and the relatively important amounts of azelaic acid (nonandioic acid), which is the principal
Fig. 5 Score plot of principal component analysis performed on data obtained from real samples, reference ointments, and raw materials by means of THM

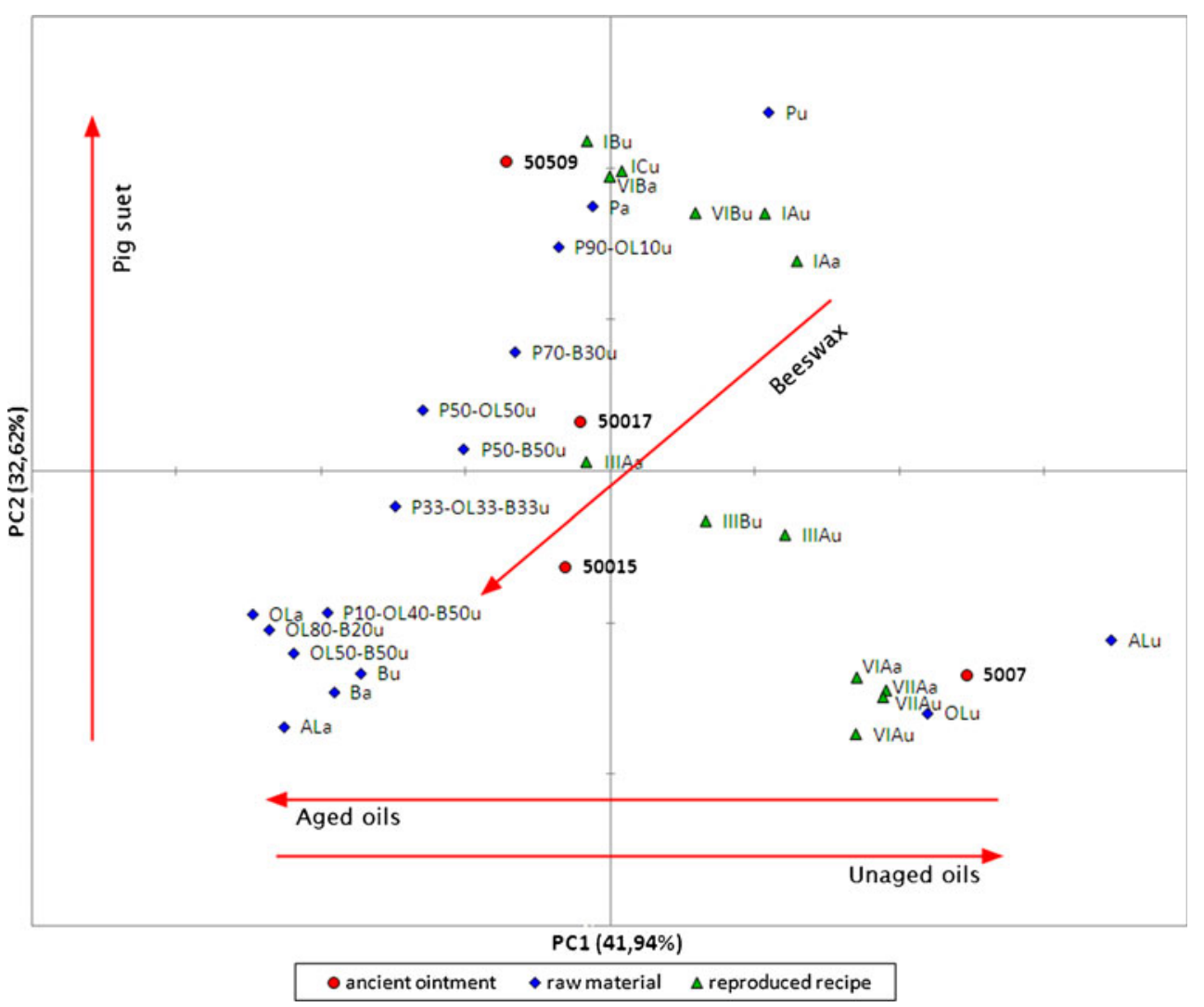


marker of aged lipids, is a truly reliable indication that these three sample are really ancient samples, not contaminated by recent materials.

\section{Conclusions}

The molecular characterization of organic constituents in ancient ointments has been pursued in this study with the application of Py-GC/MS techniques. To that goal, historical recipes of ointments have been reproduced and tested for creating a data base of results on the reference ingredients; ancient ointments have been subsequently analyzed and the compositional results compared with those from the reference materials.

In all the investigated samples, it was possible to identify the lipidic components and the natural resins. Some of the minor ingredients could not be detected, neither in the modern reproductions nor in the raw ingredients, due to the intrinsic limits of the $\mathrm{Py}-\mathrm{GC} / \mathrm{MS}$ technique. As it is generally the case, and particularly with the complex samples coming from cultural heritage artifacts, complementary information can be obtained with other diagnostic techniques, in particular from IR and Raman spectroscopy for the identification of inorganic components. For other types of organic molecules, like the dyes contained in curcuma and in turnip juice, respectively present in Unguentum althea and Unguentum pro Igne formulations, a liquid chromatography/mass spectrometry approach should be employed.

The discrimination between different kinds of lipids is indeed difficult due to the lack of precise quantification of triglycerides in the different cases. Not only is it not possible to identify the precise origin of the species, but in many cases it is also difficult to understand if the lipid comes from animal of plant source.

The use of multivariate data analysis allowed evaluation both of lipid origin and of their relative amounts in ancient samples and in modern preparations as well. The matching between recipes and ingredient amount disclosed by principal component analysis is good and allowed the validation of samples originality and of the containers labels accuracy.

Acknowledgments PRIN2007 Italian National Project is gratefully acknowledged for the financial support. The authors would also like to thank Aboca s.p.a (Italy) for the precious samples of ointments.

\section{References}

1. Martinetto P, Anne M, Dooryhée E, Drakopoulos M, Dubus M, Salomon J, Simionovici A, Walter P (2001) Synchrotron X-ray micro-beam studies of ancient Egyptian make-up. Nucl Instrum Meth B 181:744-748

2. Walter P, Martinetto P, Tsoucaris G, Bréniaux R, Lefebvre MA, Richard G, Talabot J, Dooryhee E (1999) Making make-up in ancient Egypt. Nature 397:483-484

3. Baeten J, Romanus K, Degryse P, De Clercq W, Poelman H, Verbeke K, Luypaerts A, Walton M, Jacobs P, De Vos D, Waelkens M (2010) Application of a multi-analytical toolset to a 16th century ointment: identification as lead plaster mixed with beeswax. Microchem J 95:227-234

4. Chiavari G, Prati S (2003) Analytical pyrolysis as diagnostic tool in the investigation of works of art. Chromatographia 58:543-554

5. Challinor JM (2001) Review: the development and applications of thermally assisted hydrolysis and methylation reactions. J Anal Appl Pyrol 61:3-34

6. Fabbri D, Helleur R (1999) Characterization of the tetramethylammonium hydroxide thermochemolysis products of carbohydrates. J Anal Appl Pyrol 49:277-293

7. Riedo C, Scalarone D, Chiantore O (2010) Advances in identification of plant gums in cultural heritage by thermally assisted hydrolysis and methylation. Anal Bioanal Chem 396:1559-1569

8. Papageorgiu VP, Bakola-Christianopoulou MN, Apazidou KK, Psarros EE (1997) Gas chromatographic-mass spectrometric analysis of the acidic triterpenic fraction of mastic gum. J Chromatogr A 769:263-267

9. van der Doelen GA, Jan van den Berg K, Boon JJ, Shibayama N, de la Rie RE, Genuit WJL (1998) Analysis of fresh triterpenoid resins and aged triterpenoid varnishes by high-performance liquid chromatography-atmospheric pressure chemical ionisation (tandem) mass spectrometry. J Chroma A 809:21-37

10. Evershed RP (1993) Biomolecular archeology and lipids. World Archaeol 25:74-93

11. Asperger A, Engewald W, Fabian G (2001) Thermally assisted hydrolysis and methylation - a simple and rapid online derivatization method for the gas chromatographic analysis of natural waxes. Journal of Analytical and Applied Pyrolysis 61:91-109

12. Evershed RP, Dudd SN, Colpey MS, Berstan R, Stott AW, Mottram H, Bucley SA, Crossman Z (2002) Chemistry of archaelogical animal fats. Acc Chem Res 35:660-668

13. Dudd SN, Regert M, Evershed RP (1998) Assessing microbial contributions during laboratory degradation of fats and oils and pure triacylglycerols absorbed in ceramic potsherds. Org Geochem 29:1345-1354

14. Scalarone D, Lazzari M, Chiantore O (2001) Thermally assisted hydrolysis and methylation-pyrolysis-gas chromatography:mass spectrometry of light-aged linseed oil. J Anal Appl Pyrol 5859:503-512

15. Scalarone D, Lazzari M, Chiantore O (2002) Ageing behaviour and pyrolytic characterisation of diterpenic resins used as art materials: colophony and Venice turpentine. J Anal Appl Pyrol 64:345-361 